\title{
Flow Index: a novel, non-invasive, continuous, quantitative method to evaluate patient inspiratory effort during pressure support ventilation
}

\author{
Filippo Albani', Luigi Pisani ${ }^{2,3}$, Gianni Ciabatti ${ }^{4}$, Federica Fusina ${ }^{1 *}\left(\mathbb{0}\right.$, Barbara Buizza ${ }^{5}$, Anna Granato ${ }^{1}$, \\ Valeria Lippolis ${ }^{6}$, Eros Aniballi ${ }^{7}$, Francesco Murgolo ${ }^{8}$, Antonio Rosano ${ }^{1}$, Nicola Latronico ${ }^{5,9}$, Massimo Antonelli ${ }^{10}$, \\ Salvatore Grasso ${ }^{8}$ and Giuseppe Natalini ${ }^{1}$
}

\begin{abstract}
Background: The evaluation of patient effort is pivotal during pressure support ventilation, but a non-invasive, continuous, quantitative method to assess patient inspiratory effort is still lacking. We hypothesized that the concavity of the inspiratory flow-time waveform could be useful to estimate patient's inspiratory effort. The purpose of this study was to assess whether the shape of the inspiratory flow, as quantified by a numeric indicator, could be associated with inspiratory effort during pressure support ventilation.

Methods: Twenty-four patients in pressure support ventilation were enrolled. A mathematical relationship describing the decay pattern of the inspiratory flow profile was developed. The parameter hypothesized to estimate effort was named Flow Index. Esophageal pressure, airway pressure, airflow, and volume waveforms were recorded at three support levels (maximum, minimum and baseline). The association between Flow Index and reference measures of patient effort (pressure time product and pressure generated by respiratory muscles) was evaluated using linear mixed effects models adjusted for tidal volume, respiratory rate and respiratory rate/tidal volume.

Results: Flow Index was different at the three pressure support levels and all group comparisons were statistically significant. In all tested models, Flow Index was independently associated with patient effort $(p<0.001)$. Flow Index prediction of inspiratory effort agreed with esophageal pressure-based methods.
\end{abstract}

Conclusions: Flow Index is associated with patient inspiratory effort during pressure support ventilation, and may provide potentially useful information for setting inspiratory support and monitoring patient-ventilator interactions.

Keywords: Artificial respiration, Positive-pressure respiration, Intensive care units, Patient-ventilator interaction, Inspiratory effort

*Correspondence: f.fusina@gmail.com

${ }^{1}$ Department of Anesthesia and Intensive Care, Fondazione Poliambulanza, Brescia, Italy

Full list of author information is available at the end of the article

\begin{abstract}
Background
During pressure support ventilation (PSV), assessing patient inspiratory effort could allow the titration of respiratory assistance in order to minimize over- and underassistance [1-3]. In fact, during under-assistance, a vigorous spontaneous effort may generate excessive diaphragmatic loading and muscle injury, as well as regional
\end{abstract} original author(s) and the source, provide a link to the Creative Commons licence, and indicate if changes were made. The images or other third party material in this article are included in the article's Creative Commons licence, unless indicated otherwise in a credit line to the material. If material is not included in the article's Creative Commons licence and your intended use is not permitted by statutory regulation or exceeds the permitted use, you will need to obtain permission directly from the copyright holder. To view a copy of this licence, visit http://creativecommons.org/licenses/by/4.0/. The Creative Commons Public Domain Dedication waiver (http://creativeco mmons.org/publicdomain/zero/1.0/) applies to the data made available in this article, unless otherwise stated in a credit line to the data. 
lung injury due to stress and strain [4-7]. Over-assistance, on the other hand, may lead to pulmonary hyperinflation and diaphragmatic atrophy and dysfunction, thus impairing weaning and prolonging the dependency from mechanical ventilation $[1,2,8,9]$. Independently from the appropriateness of inspiratory assistance, the patient's neuro-ventilatory drive and hence the breathing effort may unpredictably vary over time due to pain, anxiety, delirium, sepsis, sedation or other pathological conditions [10].

Despite its perceived importance, however, the inspiratory effort is seldom monitored [11]. Qualitative clinical surrogates to infer patient effort include respiratory rate $(\mathrm{RR})$, tidal volume $\left(\mathrm{V}_{\mathrm{T}}\right)$, rapid shallow breathing index (RSBI, calculated as respiratory rate over tidal volume) and the use of accessory muscles [3, 12, 13]. Esophageal pressure measurement is the reference technique used to quantify inspiratory effort, but it requires technical proficiency and the insertion of an esophageal catheter
$[14,15]$. Other methods include monitoring of the diaphragm's electrical activity and ultrasound assessment of inspiratory diaphragmatic displacement and thickness. Both are associated with drawbacks, such as availability, costs, non-continuous monitoring and operator-dependency [16].

During PSV, the inspiratory portion of the flow-time waveform may provide important information regarding patient effort. Deviations of inspiratory flow from the exponential decay pattern that is typical of the passive patient ventilated in pressumetric ventilation, suggest that the patient is active during inspiration $[17,18]$, as shown in Fig. 1. However, to our knowledge, the quantitative relationship between the inspiratory flow-time waveform and the inspiratory effort at the bedside has not been formally evaluated. In this study, we hypothesized that, during PSV, the concavity of the inspiratory flow-time waveform can be quantified by a numeric indicator, named Flow Index, similarly to the Stress Index on
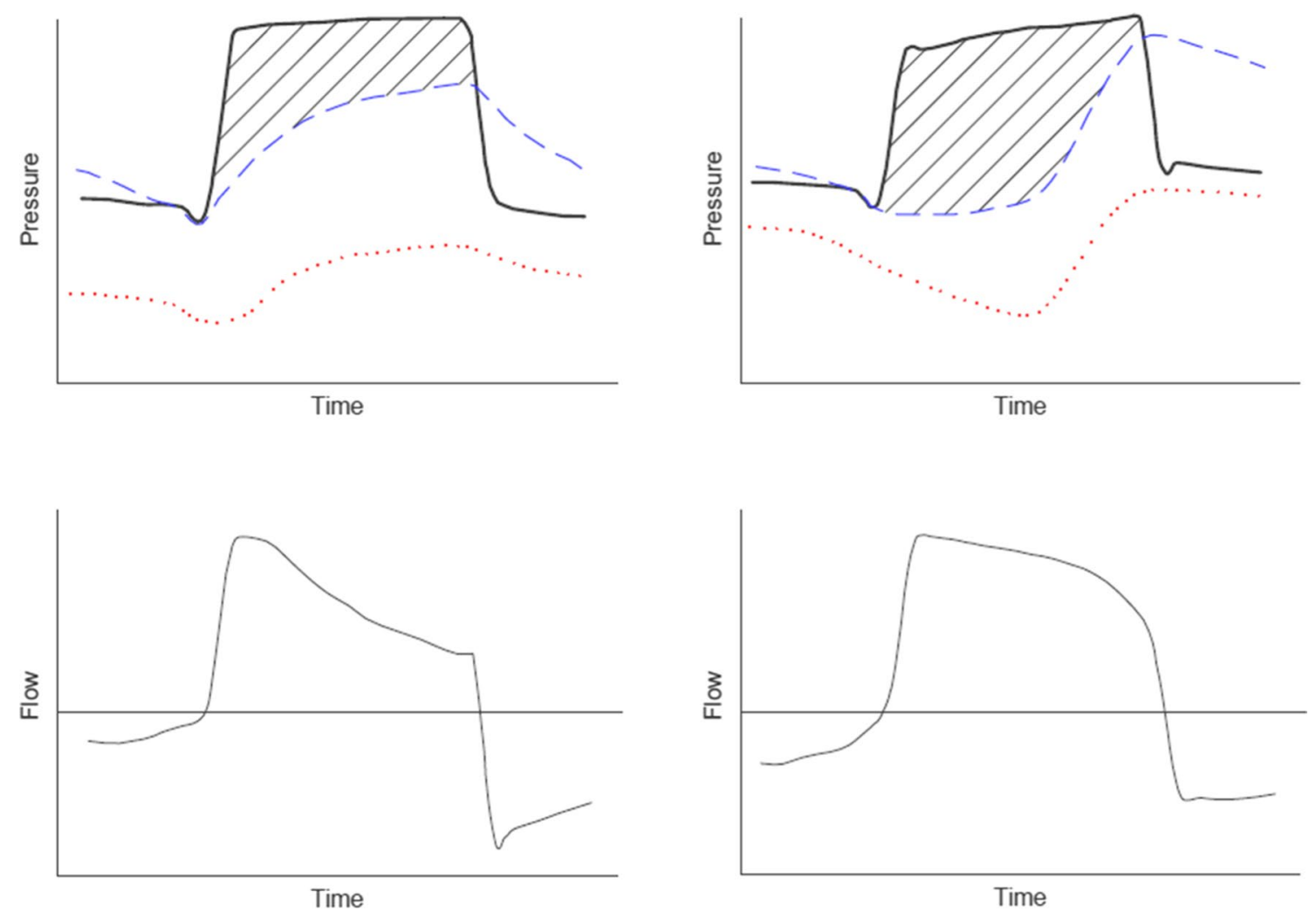

Fig. 1 Physiologic rationale behind the use of the inspiratory flow curve to detect patient inspiratory effort. The upper panels show the pressuretime curve of airway pressure $\left(P_{\text {aw, }}\right.$ full line), esophageal pressure $\left(P_{\text {es, }}\right.$ dotted line) and alveolar pressure ( $P_{\text {alv, }}$ dashed line) during pressure support ventilation. The lower panels show the flow-time curve during pressure support ventilation. Left Panels: In absence of patient inspiratory effort, the inspiratory flow is maximal at the beginning of inspiration and the pressure gradient between the airway opening and the alveoli (area with diagonal lines) is progressively reduced. Thus, the inspiratory flow parallels the exponential decay of the airway opening-alveoli pressure difference. Right Panels: In presence of patient inspiratory effort, the fall in pleural pressure reduces alveolar pressure. The greater the inspiratory effort, the more the airway-alveolar pressure gradient is sustained (area with diagonal lines). The inspiratory flow curve moves further away from the exponential decay towards a downward concavity shape, proportionally to the level of activation of inspiratory muscles 
airway opening pressure [19]. Aim of our study was to assess if Flow Index was associated with patient inspiratory effort during PSV.

\section{Methods}

\section{Patients}

This study was conducted in the Intensive Care Unit (ICU) of Fondazione Poliambulanza, Brescia, Italy. Patients were included if they met all of the following criteria: age $>18$ years, dependence on invasive mechanical ventilation (i.e. not ready to wean or having failed a spontaneous breathing trial on the day of the study [20]), being in PSV, having an esophageal balloon catheter already in place. Exclusion criteria were: mean arterial pressure $<60 \mathrm{mmHg}$, systolic arterial pressure $>180 \mathrm{mmHg}$, heart rate $<40 / \mathrm{min}$ or $>150 / \mathrm{min}, \mathrm{PaO}_{2} /$ $\mathrm{FIO}_{2}<150 \mathrm{mmHg}, \mathrm{pH}<7.35$ with $\mathrm{PaCO}_{2}>45 \mathrm{mmHg}$, diagnosis of head injury, intracranial hemorrhage or cerebral ischemia.

The protocol was approved by the local ethical committee (Comitato Etico della Provincia di Brescia). Written informed consent was obtained from the patient or, if the patients themselves were not competent, from their next of kin.

\section{Study protocol}

The pressure support (PS) level at patient enrollment was defined as baseline PS ( $\left.\mathrm{PS}_{\text {base }}\right)$. In order to explore a wide range of PS assistance, maximal and minimal PS $\left(\mathrm{PS}_{\max }\right.$ and $\mathrm{PS}_{\min }$, respectively) were titrated. The $\mathrm{PS}_{\max }$ was sought by progressively increasing the PS level until all signs of inspiratory muscle activity disappeared after inspiratory triggering, as assessed by visual inspection of the waveform of esophageal pressure $\left(\mathrm{P}_{\mathrm{es}}\right)$, airway opening pressure $\left(\mathrm{P}_{\mathrm{aw}}\right)$ and airflow. In order to avoid lung injury, the peak airway pressure was limited to a maximum of $30 \mathrm{cmH}_{2} \mathrm{O}$, regardless of achieving complete absence of inspiratory muscle activity. The $\mathrm{PS}_{\min }$ was identified as the lowest PS level without dyspnea, keeping the $\mathrm{RSBI}<100 \mathrm{~min}^{-1} \mathrm{l}^{-1}$. Apart from the PS level, all the remaining ventilation variables $\left(\mathrm{FIO}_{2}\right.$, inspiratory trigger, expiratory trigger) remained constant, as previously set by the attending physician. $\mathrm{PS}_{\text {base }}, \mathrm{PS}_{\min }$ and $\mathrm{PS}_{\max }$ were delivered in random order to every patient for 20 min each. PS levels were applied without interruption, and the recordings were obtained after letting the patient adapt for 20 min to each new PS level.

\section{Measurements and calculations}

Pes was measured by an esophageal balloon catheter (Marquat Gbm, Boissy-St-Léger Cedex, France) connected to a pressure transducer (AS3/CS3; DatexEngstrom Division, Instrumentarium Corp., Helsinki,
Finland). The esophageal balloon was introduced $40 \mathrm{~cm}$ from the nostril and inflated with $1 \mathrm{ml}$ of air. The occlusion test was used to assess if the $\mathrm{P}_{\mathrm{es}}$ was appropriately transduced [21, 22]. The position of the balloon in the esophagus and its filling volume were modified, if necessary, so as to obtain a ratio between $\mathrm{P}_{\mathrm{es}}$ and $\mathrm{P}_{\mathrm{aw}}$ swings ranging between 0.8 and 1.2 during the occlusion [23, 24].

$\mathrm{P}_{\mathrm{aw}}$, airflow, volume and $\mathrm{P}_{\mathrm{es}}$ waveforms were recorded for each PS level for $5 \mathrm{~min}$ at the sampling rate of $100 \mathrm{~Hz}$ (Datex-Ohmeda S/5 Collect; Datex-Ohmeda Division, Instrumentarium Corp., Helsinki, Finland). Mean tidal volume $\left(\mathrm{V}_{\mathrm{T}}\right)$ and respiratory rate $(\mathrm{RR})$ were also obtained for each patient at the 3 levels of PS. The RSBI was calculated as $\mathrm{RR} / \mathrm{V}_{\mathrm{T}}$.

All measurements were obtained from the longest portion of the esophageal pressure waveform without swallowing artifacts (detected by a transient, sudden increase on the pressure trace), recorded at the end of the $20 \mathrm{~min}$ at each PS level.

The onset of inspiration was identified by the first positive value in the flow recording, while the end of inspiration was identified by the last positive value of the inspiratory flow. The static recoil pressure of the chest wall $\left(\mathrm{P}_{\mathrm{cw}}\right)$ was calculated as the product of the inspired $\mathrm{V}_{\mathrm{T}}$ and the measured chest wall elastance $\left(\mathrm{E}_{\mathrm{cw}}\right) . \mathrm{E}_{\mathrm{cw}}$ was calculated as the ratio between the inspiratory change in $\mathrm{P}_{\mathrm{es}}$ [end-inspiratory plateau esophageal pressure $\left(\mathrm{P}_{\text {plat,es }}\right)$ minus end-expiratory plateau esophageal pressure $\left.\left(\mathrm{P}_{\text {expes }}\right)\right]$ and $\mathrm{V}_{\mathrm{T}}$ obtained during $\mathrm{PS}_{\max }$, i.e. in a condition of near relaxation.

The pressure generated by inspiratory muscles $\left(\mathrm{P}_{\text {musc }}\right)$ was calculated as the maximal difference between $P_{c w}$ and $\mathrm{P}_{\mathrm{es}}$ (Fig. 2). The Pressure-Time Product of a single breath $\left(\mathrm{PTP}_{\mathrm{pt}, \text { breath }}\right)$ was calculated as the area between $\mathrm{P}_{\mathrm{cw}}$ and $\mathrm{P}_{\mathrm{es}}$ during tidal inspiration (Fig. 2). Similarly, the PTP of the mechanical ventilator for each breath $\left(\mathrm{PTP}_{\text {vent,breath }}\right)$ was obtained as the area between the $\mathrm{P}_{\mathrm{aw}}$ and the set PEEP during inspiration. The total PTP $\left(\mathrm{PTP}_{\text {tot, breath }}\right)$ was the sum of PTP $\mathrm{pt}_{\text {tbreath }}$ and $\mathrm{PTP}_{\text {vent,breath }}$. The fraction of PTP generated by the patient during pressure support ventilation ( $\mathrm{PTP}_{\text {ratio,breath) }}$ was calculated as follows:

$$
\mathrm{PTP}_{\text {ratio,breath }}=\mathrm{PTP}_{\mathrm{pt}, \text { breath }} / \mathrm{PTP}_{\text {tot,breath }}
$$

\section{The Flow Index}

The portion of the inspiratory flow-time waveform included between the end of the ramp and before the expiratory trigger was used to calculate the Flow Index (Fig. 3). A non-linear model, described by Eq. 2, was fitted to this portion of the flow waveform for every breath analyzed. 
Fig. 2 Airway pressure $\left(P_{a w}\right)$, esophageal pressure $\left(P_{e s}\right)$ and airflow curves from a study participant. Upper panel: airway pressure $\left(P_{a w}\right)$ curve. The inspiratory phase is identified by dashed vertical lines, while the Pressure Time Product of the ventilator $\left(\right.$ PTP $\left._{\text {vent }}\right)$ is identified by the blue area, that is calculated as the product of inspiratory pressure $\left(\mathrm{P}_{\mathrm{aw}}\right.$ minus positive end expiratory pressure) for the duration of inspiration. Middle panel: esophageal pressure $\left(P_{\text {es }}\right)$ curve. The chest wall elastic recoil pressure $\left(P_{c w}\right)$ is identified by a dot-dashed line, while the Pressure Time Product of the patient $\left(\right.$ PTP $\left._{\text {pt,breath }}\right)$ is identified by the red area calculated as the product of $P_{c w}$ minus $P_{\text {es }}$ for the duration of inspiration. The maximum pressure generated by respiratory muscles $\left(P_{\text {musc }}\right)$ is identified by the arrow. Lower panel: inspiratory flow trace

$$
\dot{V}=a+\mathrm{b} \cdot \Delta \text { time }^{c}
$$

In this model, the inspiratory flow $(\dot{V})$ is a function of time, of peak flow $(A)$, of the rate of flow reduction $(b)$ and of parameter $c$, which describes the downward facing concavity of the portion of the inspiratory flow waveform. The parameter $c$, calculated for every breath, was named Flow Index. The inspiratory flow waveform was automatically cut at two different points, in order to select its descending portion and estimate the parameter $c$ or Flow Index (Fig. 3). The initial cut point was selected by excluding all the measurements in which the flow increased more than $1 \%$ of the preceding measurement, meaning that flow trace quickly increased towards its peak with the rate of increase depending on the ramp. The final cut point was identified as the point where the measured flow decreased more than $10 \%$ of the preceding measurement, indicating the beginning of the cycling toward expiration. The portion of the flow trace between the initial and the final cut point was used to estimate the Flow Index by fitting a non-linear model, as described by Eq. 2.

The Flow Index describes the concavity of the curve using the same equation that computes the wellknown Stress Index, a visual and quantitative parameter of overdistension detectable from the inspiratory airway opening pressure profile during constant-flow controlled mechanical ventilation $[19,25,26]$. The Flow Index is equal to 1 when the inspiratory flow decreases linearly. If the waveform has an upward facing concavity, the Flow Index is $<1$, whereas if the curve has a downward facing concavity, the Flow Index is $>1$. The principle supporting visual inspection of the inspiratory decay of the airflow waveform
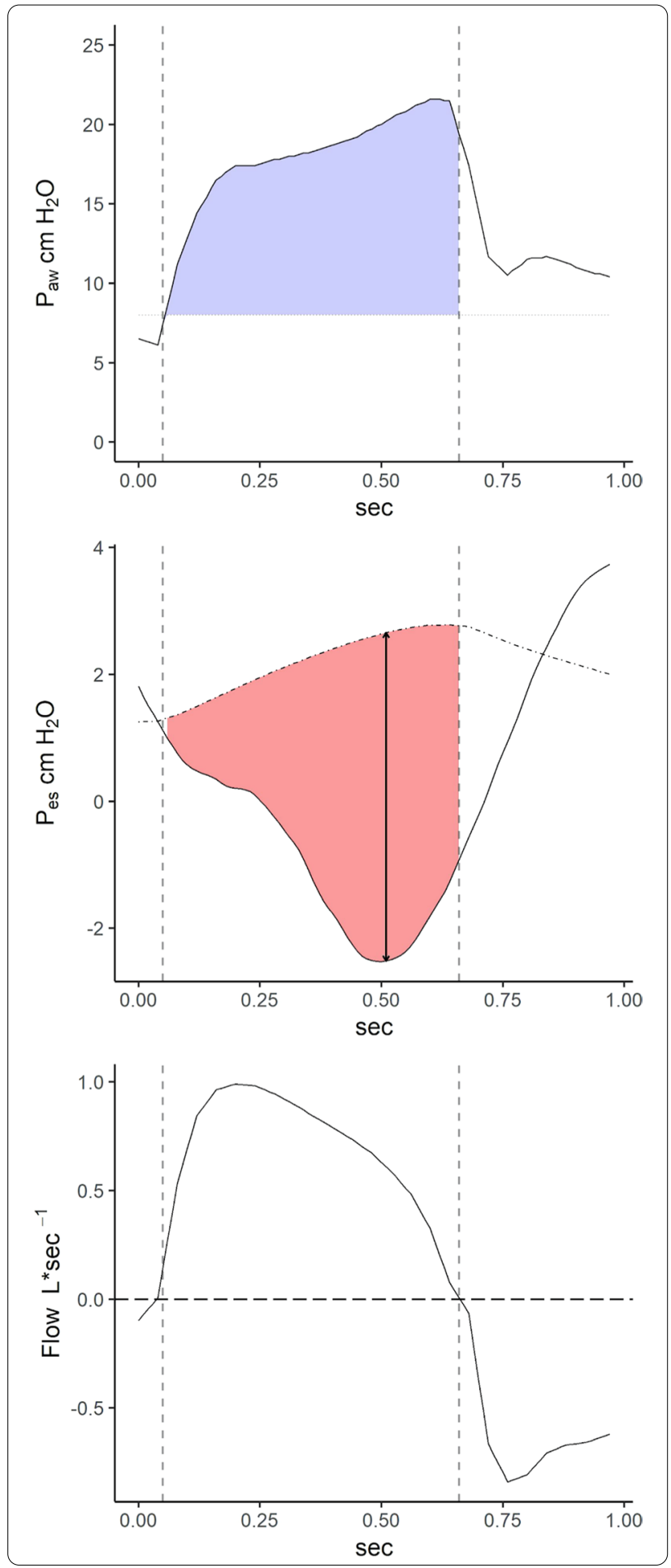


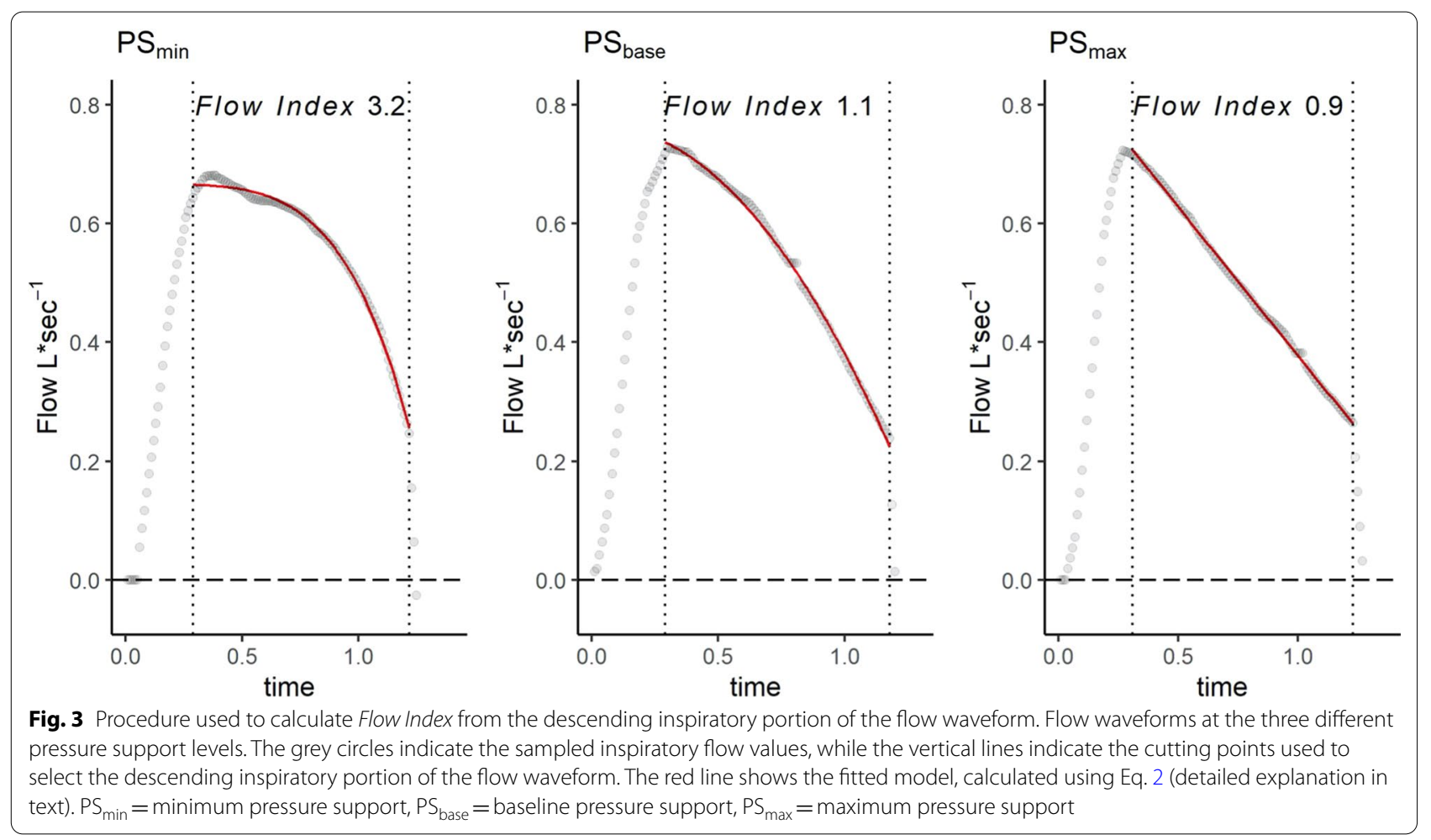

to estimate patient effort has been previously suggested $[17,18]$. The Flow Index rationale arises from the analysis of the inspiratory flow during pressometric mechanical ventilation in the passive patient, which is characterized by constant pressure applied to the airway opening throughout the entire inspiratory time. The inspiratory flow is driven by the difference of pressure between the airway opening and alveoli, which is maximal at the beginning of inspiration when the alveoli have their minimal pressure (Fig. 1). Thus, in absence of patient inspiratory effort, the inspiratory flow is maximal at the beginning of inspiration. If a patient remains passive throughout the inspiration, alveolar pressure exponentially increases as the volume fills the alveoli, proportional to the elastance of the respiratory system. This progressively decreases the pressure gradient between the airway opening and the alveoli, and inspiratory airflow parallels the exponential decay of the opening airway-alveoli pressure difference. When a patient activates the inspiratory muscles during the inspiratory phase, the fall in pleural pressure tends to increase the chest wall and lung volume, decreasing the alveolar pressure. Thus, the greater the inspiratory effort, the more the gradient between airway opening and alveolar pressure will be sustained. This mechanism increases the instantaneous inspiratory flow as compared to the passive condition and modifies its shape profile, from an exponential decay towards a downward concavity (Fig. 1). We hypothesized that these changes in the inspiratory waveform profile, as quantified by the Flow Index, would be proportional to the activation of the inspiratory muscles and thus useful to quantify patient inspiratory effort.

\section{Outcomes}

The primary outcome was the association between the Flow Index and patient respiratory effort, as expressed by $\mathrm{PTP}_{\text {pt,breath }}, \mathrm{PTP}_{\text {ratio,breath }}$ and $\mathrm{P}_{\text {musc }}$.

\section{Statistical analysis}

We planned to assess sample size after enrolling the first 20 patients. A power analysis was carried out using Montecarlo simulation, employing a linear mixed model with a random effect for each patient. Enrolling 24 patients would grant a power of $85 \%$ with alpha $=0.05$ to detect an effect size of $0.10 \mathrm{cmH}_{2} \mathrm{O} \cdot \mathrm{s}^{-1}$ increment in PTP $_{\text {pt,breath }}$ for each unitary increase in Flow Index.

Data are shown as mean \pm standard deviation, median (1st-3rd quartile) or frequency (percentage), as appropriate. Variables at the three levels of support were compared with analysis of variance (ANOVA) for repeated measure and post-hoc Tukey's honestly significant difference (HSD) test. 
Table 1 Patients' characteristics

\begin{tabular}{|c|c|}
\hline Age (years) & $74 \pm 9.7$ \\
\hline Female, $n(\%)$ & $6(25)$ \\
\hline Body Mass Index $\left(\mathrm{kg} \mathrm{m}^{-2}\right)$ & $26.7 \pm 6.7$ \\
\hline Height (cm) & $168 \pm 8.6$ \\
\hline Days on mechanical ventilation at enrollment & $9(3-21)$ \\
\hline Patients with tracheostomy on study day, $n(\%)$ & $7(30)$ \\
\hline $\operatorname{PEEP}\left(\mathrm{cmH}_{2} \mathrm{O}\right)$ & $6 \pm 1$ \\
\hline $\mathrm{FIO}_{2}$ & $0.4 \pm 0.08$ \\
\hline $\mathrm{pH}$ & $7.46 \pm 0.04$ \\
\hline $\mathrm{PaCO}_{2}(\mathrm{mmHg})$ & $38 \pm 5$ \\
\hline $\mathrm{PaO}_{2}(\mathrm{mmHg})$ & $88 \pm 25$ \\
\hline Hospital mortality, $n(\%)$ & $4(16 \%)$ \\
\hline Length of stay in Intensive Care Unit (days) & $25(15-35)$ \\
\hline \multicolumn{2}{|l|}{ Diagnosis } \\
\hline ARDS & $12(50 \%)$ \\
\hline COPD exacerbation & $5(21 \%)$ \\
\hline Sepsis & $10(42 \%)$ \\
\hline Trauma & $3(13 \%)$ \\
\hline
\end{tabular}

Data are shown as mean (standard deviation) or count (\%). Measurements were taken at the time of patient enrollment

PEEP positive end expiratory pressure, ARDS acute respiratory distress syndrome, COPD chronic obstructive pulmonary disease effects. These models were compared with a likelihood ratio test to a model including Flow Index, to assess if Flow Index improved the goodness of fit [27]. Marginal $R^{2}$ and conditional $R^{2}$ were computed, expressing the amount of variance in the dependent variable which could be explained by the mixed models, respectively excluding and including the variance explained by the random effect in the models [28].

In order to explore the association between Flow index and the $\mathrm{PTP}_{\mathrm{pt} \text {,breath }}$ for every single patient, we estimated 24 linear models, one for each patient (see Additional file 1: Fig. S1).

A $p$ value lower than 0.05 was considered significant. Statistical analyses were performed with $\mathrm{R}$ ( $\mathrm{R}$ Core Team, 2018. R Foundation for Statistical Computing, Vienna, Austria) with packages "lme4" (version 1.1-21), "multcomp" (version 1.4-11).

\section{Results}

A total of 24 patients were included in the study. Patients' characteristics are shown in Table 1. Breathing pattern, levels of inspiratory effort and Flow Index at the three levels of PS are shown in Table 2. The increase in PS level was associated with higher $V_{T}$ and lower $R R$, with similar

Table 2 Inspiratory effort and breathing pattern at $P S_{\text {min }}, P S_{\text {base }}$ and $P S_{\max }$

\begin{tabular}{|c|c|c|c|c|}
\hline & $\mathrm{PS}_{\min }$ & $\mathrm{PS}_{\text {base }}$ & $\mathrm{PS}_{\max }$ & $P$ value \\
\hline Set pressure support level $\left(\mathrm{cmH}_{2} \mathrm{O}\right)$ & $4 \pm 1$ & $10 \pm 3$ & $18 \pm 5$ & $<0.001$ \\
\hline Tidal volume (ml) & $440 \pm 132$ & $511 \pm 146$ & $671 \pm 217$ & $<0.001$ \\
\hline Tidal volume/IBW $\left(\mathrm{ml} \mathrm{kg}^{-1}\right)$ & $6.6(1.7)$ & $7.9(1.9)$ & $10.5(2.4)$ & $<0.001$ \\
\hline Respiratory rate $\left(\mathrm{min}^{-1}\right)$ & $31 \pm 10$ & $26 \pm 10$ & $20 \pm 6$ & $<0.001$ \\
\hline $\mathrm{RSBI}$ & $78 \pm 36$ & $58 \pm 31$ & $34 \pm 19$ & $<0.001$ \\
\hline Minute ventilation $\left(\mid \mathrm{min}^{-1}\right)$ & $11.6 \pm 4.0$ & $11.7 \pm 4.3$ & $11.7 \pm 3.9$ & 0.98 \\
\hline $\operatorname{PTP}_{\text {pt,minute }}\left(\mathrm{cmH}_{2} \mathrm{O} \cdot \mathrm{s} \mathrm{min}^{-1}\right)$ & $83 \pm 93$ & $32 \pm 94$ & $8 \pm 26$ & $<0.001$ \\
\hline PTP $p_{\text {pt,breath }}\left(\mathrm{cmH}_{2} \mathrm{O} \cdot \mathrm{s}\right)$ & $4.0(2.9)$ & $2.3(2.2)$ & $0.9(1.4)$ & $<0.001$ \\
\hline PTP ratio,breath & $0.76 \pm 0.3$ & $0.29 \pm 0.28$ & $0.06 \pm 0.09$ & $<0.001$ \\
\hline$P_{\text {musc }}\left(\mathrm{cmH}_{2} \mathrm{O}\right)$ & $7.5(4.4)$ & $4.3(3.6)$ & $1.9(2.6)$ & $<0.001$ \\
\hline Flow Index & $4.6 \pm 3.3$ & $3.3 \pm 2.5$ & $1.9 \pm 1.3$ & $<0.001$ \\
\hline
\end{tabular}

All pairwise comparisons between the three PS levels were significant $(p<0.05)$, except for minute ventilation

$\mathrm{PS}_{\min }=$ minimal pressure support, $\mathrm{PS}_{\text {base }}=$ baseline pressure support, $\mathrm{PS}$ max $=$ maximal pressure support, $\mathrm{RSBI}=\mathrm{Rapid}$ Shallow Breathing Index obtained by the ratio of respiratory rate and $\mathrm{V}_{T}, \mathrm{PTP}_{\mathrm{pt} \text {,minute }}=$ Pressure-time product for the patient in one minute, $\mathrm{PTP}_{\mathrm{pt}, \text { breath }}=$ Pressure-time product for the patient in a single breath, $\mathrm{PTP}_{\text {ratio,breath }}=\mathrm{PTP}_{\text {pt, breath }} /\left(\mathrm{PTP}_{\mathrm{pt} \text {, breath }}+\mathrm{PTP}_{\text {vent, breath }}\right), \mathrm{P}_{\text {musc }}=$ pressure generated by respiratory muscles

Flow Index was compared in the different quartiles of inspiratory effort estimates $\left(\mathrm{PTP}_{\mathrm{pt} \text {,breath}}\right.$, $\mathrm{PTP}_{\text {ratio,breath }}$ and $\mathrm{P}_{\text {musc }}$ ) with ANOVA for repeated measures and post-hoc Tukey's HSD test.

Linear mixed effects models were used to assess the association between Flow Index and $\mathrm{PTP}_{\text {pt,breath }}$, $\mathrm{PTP}_{\text {ratio,breath }}$ and $\mathrm{P}_{\text {musc }}$, both unadjusted and adjusted for $R R$ and $V_{T}$, with patients managed as random minute ventilation. The level of inspiratory effort significantly decreased by raising PS levels.

\section{Association between Flow Index and inspiratory effort}

Flow Index was different at the three PS levels and all group comparisons were statistically significant at the post hoc analysis $\left(\mathrm{PS}_{\text {base }}\right.$ vs. $\mathrm{PS}_{\min } p=0.005 ; \mathrm{PS}_{\text {base }}$ vs. $\mathrm{PS}_{\max } p<0.001 ; \mathrm{PS}_{\max }$ vs. $\left.\mathrm{PS}_{\min } p<0.001\right)$. Figure 4 shows, 

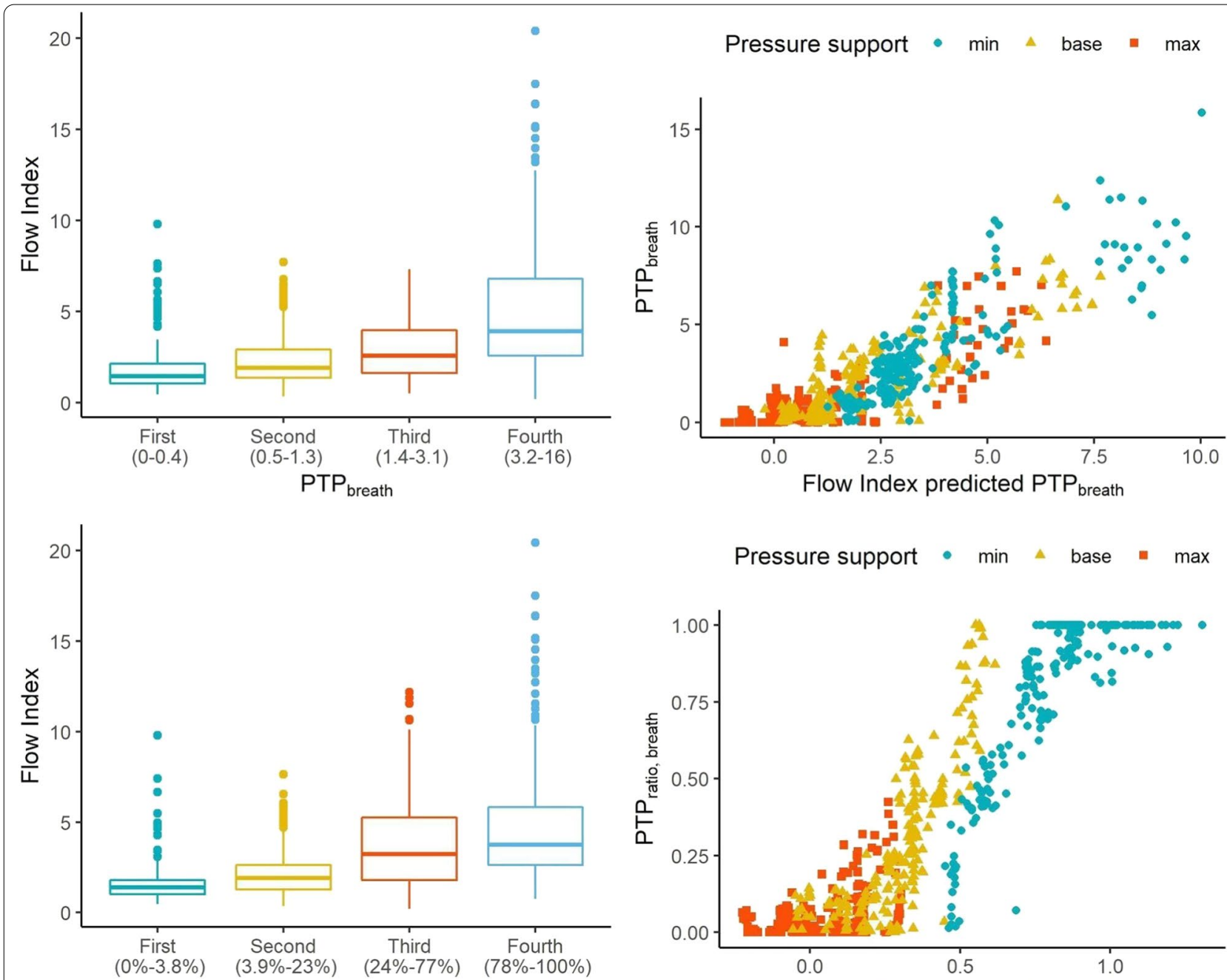

PTP ratio, breath
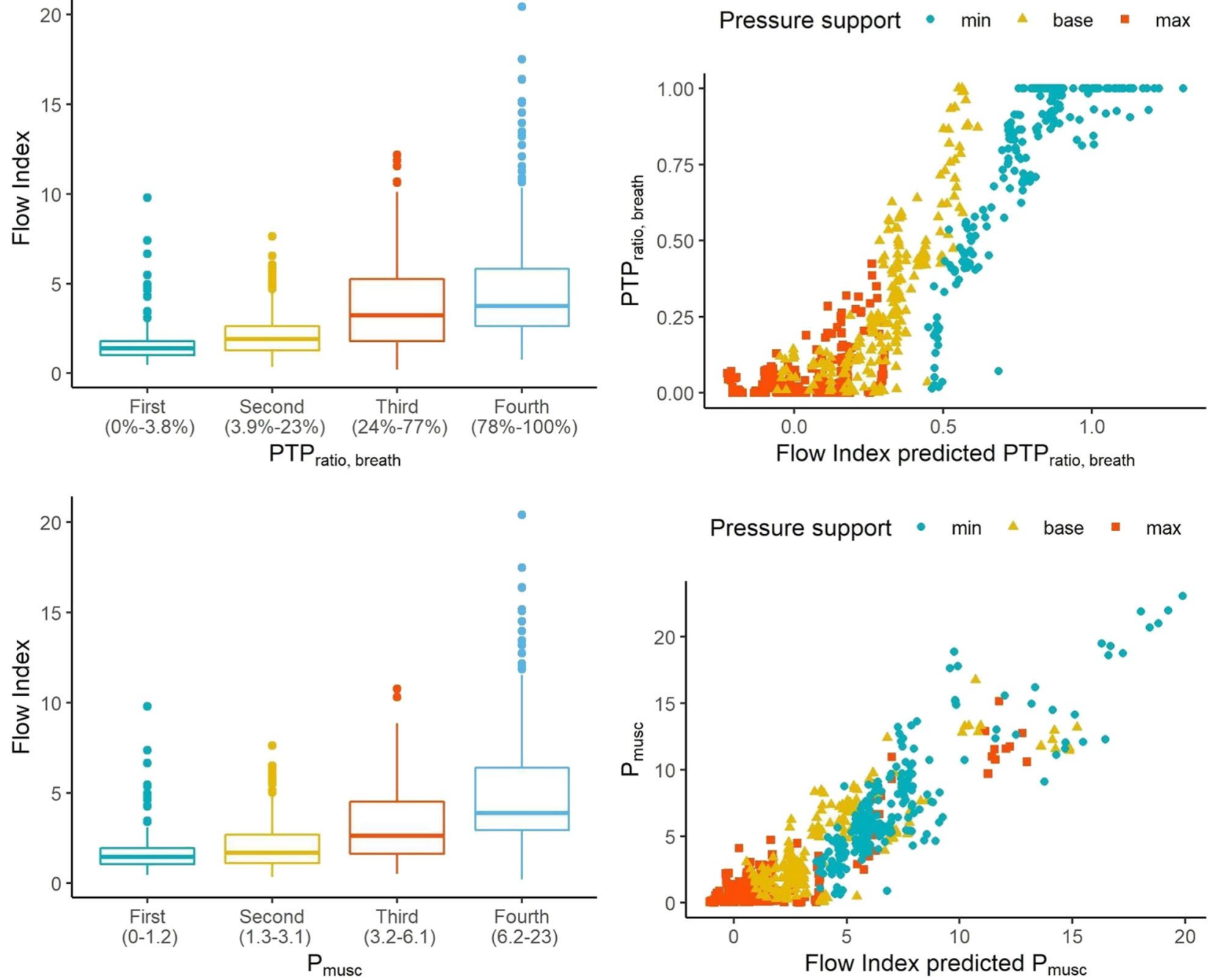

Fig. 4 Box plot of quartiles of respiratory effort and Flow Index. Scatter plot of Flow Index model prediction and measured pressure time product, pressure time product ratio and muscular pressure. Left column: box plot of Flow Index in quartiles of inspiratory effort as evaluated with PTP ${ }_{\mathrm{pt}}$, breath' PTP $_{\text {ratio,breath }}$ and $\mathrm{P}_{\text {musc }}$. Right column: scatter plot of Flow Index model prediction for PTP $P_{\text {pt, breath }}$ PTP ratio,breath and $\mathrm{P}_{\text {musc }}$ compared with measured PTP $_{\text {pt, breath, }}$ PTP ratio,breath and $P_{\text {musc }}$. Different PS levels are identified with different colors, as indicated above each panel. PTP $=$ pressure time product 
Table 3 Flow Index coefficient of unadjusted and adjusted linear mixed effects models

\begin{tabular}{|c|c|c|c|c|}
\hline & Flow Index coefficient $(95 \% \mathrm{Cl})$ & $P$ value & $\begin{array}{l}\text { Flow Index coefficient }(95 \% \mathrm{Cl}) \text { adjusted } \\
\text { for RR and } \mathrm{V}_{\mathrm{T}}\end{array}$ & $P$ value \\
\hline PTP ratio, breath & $0.03(0.03,0.04)$ & $<0.0001$ & $0.03(0.03,0.04)$ & $<0.0001$ \\
\hline PTP $_{\text {pt,breath }}$ & $0.19(0.13,0.25)$ & $<0.0001$ & $0.23(0.17,0.29)$ & $<0.0001$ \\
\hline$P_{\text {musc }}$ & $0.34(0.24,0.43)$ & $<0.0001$ & $0.33(0.230 .42)$ & $<0.0001$ \\
\hline
\end{tabular}

$P_{\text {musc }}=$ pressure generated by respiratory muscles

on the left side, the boxplots of Flow Index at different quartiles of $\mathrm{PTP}_{\text {pt,breath }}$, $\mathrm{PTP}_{\text {ratio,breath }}$ and $\mathrm{P}_{\text {musc }}$. All the comparisons were statistically significant $(p<0.01)$, except for those between the first and second quartile. On the right side, Fig. 4 shows the scatter plots of Flow Index-predicted against measured $\mathrm{PTP}_{\text {breath }}, \mathrm{PTP}_{\text {ratio,breath }}$ and $\mathrm{P}_{\text {musc }}$. Table 3 shows the coefficients of association resulting from the linear effects models between Flow Index and $\mathrm{PTP}_{\mathrm{pt}, \text { breath }}$, $\mathrm{PTP}_{\text {ratio,breath }}, \mathrm{P}_{\text {musc }}$, both unadjusted and adjusted for RR and $\mathrm{V}_{\mathrm{T}}$.

Moreover, in 22 out of 24 patients there was a positive and statistically significant association between Flow Index and the $\mathrm{PTP}_{\mathrm{pt} \text {,breath }}$ for every single patient (see Additional file 1: Fig. S1).

\section{Comparison between models}

The model fit significantly improved when the Flow Index was added to $R R$ and $V_{T}$ ( $p$ value for the likelihood ratio test $<0.001$ for $\mathrm{PTP}_{\text {pt,breath }}$, $\mathrm{PTP}_{\text {ratio,breath }}$ and $\mathrm{P}_{\text {musc }}$ ), indicating that the Flow Index improved the inspiratory effort prediction.

The model for $\mathrm{P}_{\text {musc }}$ estimated an increase of 0.33 $(95 \% \mathrm{CI} 0.23,0.42) \mathrm{cmH}_{2} \mathrm{O}$ for each unitary increase in Flow Index (conditional $R^{2} 0.77$ ), the estimated increase in $\mathrm{PTP}_{\text {pt,breath }}$ was $0.23(95 \% \mathrm{CI} 0.17-0.29) \mathrm{cmH}_{2} \mathrm{O} \cdot \mathrm{s}^{-1}$ for each unitary increase in Flow Index (conditional $R^{2}$ $0.7)$, while each unitary increase in Flow Index was associated with an increase of $3.2 \%$ (95\% CI $2.5-3.9 \%)$ in $\mathrm{PTP}_{\text {ratio,breath }}$ (conditional $R^{2}$ 0.86).

\section{Discussion}

This study shows that Flow Index is independently associated with patient inspiratory effort and can give information on patient-ventilator interaction and on the distribution of respiratory effort between patient and ventilator.

We found that the Flow Index gives more insight on patient effort than the traditional analysis of the respiratory pattern based on the evaluation of $R R$ and $V_{T}$. This is a remarkable result since in clinical practice the inspiratory effort is seldom measured, and $R R$ and $V_{T}$ are deemed as useful surrogates for setting the PSV level [29]. Indeed, PSV level is usually titrated to obtain a VT between 5 and $8 \mathrm{ml} / \mathrm{kg}$ predicted body weight (PBW) and a RR between 20 and 30 breaths/min $[6,10]$. The RSBI [13], which, by expressing an imbalance between load and effort, could be deemed as a sign of inadequate inspiratory support was not taken into account in the primary analysis since our model included both $R R$ and $V_{T}$. Nonetheless, we performed an unplanned post hoc supplementary analysis evaluating the association between Flow Index and RSBI. The results are similar to the ones we obtained for RR and VT.

The analysis of the respiratory waveforms is an essential bedside activity for intensivists but, to our knowledge, this is the first attempt to assess patient inspiratory effort based on the quantitative analysis of the inspiratory flow-time waveform, since all available evaluations of patient inspiratory effort are focused on the inspection of the pressure curve.

In this study the association between Flow Index and respiratory effort was assessed in a wide range of inspiratory efforts, as witnessed by the fact $\mathrm{PT}_{\text {pt,breath }}$ and $\mathrm{P}_{\text {musc }}$ were $400 \%$ higher at $\mathrm{PS}_{\min }$ than at $\mathrm{PS}_{\max }$. Since measuring the Flow Index is relatively simple, continuous and noninvasive, we suggest that this parameter could be suitable to titrate and monitor patient-ventilator interactions during PSV. However, this was a physiological study and further studies are needed to evaluate if the setting of PSV according to the Flow Index or monitoring the inspiratory effort during PSV over time could have an impact on clinically meaningful outcome parameters.

Since Flow Index is measured on a single breath, it was gauged against other single breath indicators of patient effort $\left(\mathrm{PT}_{\mathrm{pt}, \text { breath }}, \mathrm{P}_{\text {musc }}\right.$ and $\left.\mathrm{PT}_{\text {ratio,breath }}\right)$. Theoretically the best association with Flow Index could be with $\mathrm{PT}_{\text {ratio,breath }}$, since the latter depends on the interaction between support from the ventilator and patient effort. Nonetheless, our data show a strong association between Flow Index, $\mathrm{PT}_{\mathrm{pt}, \text { breath }}$ and $\mathrm{P}_{\text {musc }}$. Accordingly, the Flow Index may be taken as a surrogate of the absolute patient inspiratory effort, as expressed with $\mathrm{P}_{\text {musc }}$ or $\mathrm{PT}_{\mathrm{pt} \text {,breath }}$.

Several invasive and non-invasive estimates of patient effort were proposed in recent decades [3]. The pressure muscle index (PMI) and the least square fitting method (LSF) were among the first ones that were advanced. 
These techniques, however, required intermittent inspiratory occlusions or complex calculations, respectively, and their accuracy in evaluating single breath inspiratory effort was scarcely accurate [30-32]. Of note, PMI evaluates end-inspiratory effort only and not the overall effort during inspiration, since it does not take into account the inspiratory resistive load. A recent study showed a significant association between the negative swing in $\mathrm{P}_{\mathrm{aw}}$ generated by respiratory muscle effort during assisted ventilation when the airway is briefly occluded $\left(\mathrm{P}_{\text {occl }}\right)$ and patient inspiratory effort. Though this method is of interest, a manual occlusion is needed and $\mathrm{P}_{\text {occl }}$ could not provide continuous monitoring of patient inspiratory effort [11]. The assessment of diaphragmatic electrical activity (Edi) is an accurate measure of neuro-ventilatory drive, and $\mathrm{P}_{\text {musc }}$ may be estimated through the calculation of neuromuscular efficiency, obtained by comparing Edi and $\mathrm{P}_{\mathrm{occl}}$ during an end-expiratory airway occlusion, or through the calculation of neuro-ventilatory efficiency, obtained by comparing $\mathrm{E} d i$ and $\mathrm{V}_{\mathrm{T}}[10,33,34]$. However, measuring $\mathrm{E} d i$ is costly, requires the insertion of a patent-protected nasogastric catheter which functions only with specific mechanical ventilators and, finally, a manual occlusion is required to calculate neuromuscular efficiency [33]. Moreover, during inspiratory effort the contribution of diaphragm and other inspiratory muscles may vary, since a great variability in diaphragm contribution to inspiration exists (as can be seen, for example, between male and female patients [34-36]). Edi allows detection of the diaphragm contribution exclusively, and therefore it can lead to loss of important information for patients in whom the diaphragm contribution is low [33]. Diaphragm ultrasound has also been proposed as a tool to estimate patient effort, but it remains a punctual measure, dependent on the operator's technical ability and heavily influenced by the degree of diaphragm dysfunction $[37,38]$.

Strengths of the Flow Index are its non-invasiveness, the possibility to monitor it continuously and the independence from occlusion maneuvers which is particularly advantageous since not all mechanical ventilators permit a manual expiratory occlusion during PSV [39, 40]. Since the flow waveform is displayed on the majority of mechanical ventilators, visual inspection of Flow Index by trained physicians could also give valuable information, albeit only qualitative, on inspiratory effort. More studies are needed to know if visual inspection of the flow waveform is sufficient to assess Flow Index, but since the Stress Index uses a similar equation and its visual inspection has been proved to be effective [25], the same may be applicable to Flow Index. Of note, the Flow Index algorithm could be easily implemented on standard monitoring, as has been done for the Stress Index [19], permitting a quantitative evaluation of patient effort during mechanical ventilation.

This study presents four main limitations. First, it is a single center study, and therefore its external validity needs to be proved by additional studies. Second, some portions of the inspiratory effort are not included in the calculation of Flow Index, since they occur before the peak inspiratory flow is reached. Despite this potential limitation, the Flow Index shows a good association with the post-triggering inspiratory effort. This could be due to the fact that the rise time usually lasts a really short time (less than $100 \mathrm{~ms}$ ), and therefore has little impact on the patient's overall inspiratory effort. Third, the Flow Index should be specifically assessed in patients with a high resistive load, in which a high respiratory effort may not correspond to a proportional increase in inspiratory flow. Of note, the Flow Index does not account for patient effort before the inspiratory flow, which should be considered in patients with severe dynamic hyperinflation. Fourth, our study does not give any cutoffs useful to detect high or low inspiratory effort, and further studies should assess this relevant aspect.

\section{Conclusions}

Flow Index is a novel quantitative, continuous, noninvasive evaluation of the concavity of the inspiratory flow profile. Our study show that the Flow Index is associated with patient inspiratory effort during PSV and that it gives additional information when compared to the variables traditionally used for inspiratory effort evaluation during pressure support ventilation (i.e. $\mathrm{V}_{\mathrm{T}}$, $\mathrm{RR}$ and RSBI). Additional research is needed to evaluate the potential impact of assessing the Flow Index on patient-ventilator interaction and weaning from mechanical ventilation.

\footnotetext{
Abbreviations

ANOVA: analysis of variance; $E$ di: diaphragmatic electrical activity; $E_{c w}$ : measured chest wall elastance; HSD: honestly significant difference; ICU: Intensive Care Unit; LSF: least square fitting method; PSV: pressure support ventilation; PS: pressure support; PS $_{\text {base }}$ : baseline pressure support; PS $_{\text {max }}$ : maximal pressure support; $\mathrm{PS}_{\min }$ : minimal pressure support; $P_{\mathrm{es}}$ : esophageal pressure; $\mathrm{P}_{\mathrm{aw}}$ : airway opening pressure; $P_{c w}$ : static recoil pressure of the chest wall; $P_{\text {musc: }}$ pressure generated by respiratory muscle; $P_{\text {plat,es: }}$ end-inspiratory plateau esophageal pressure; $P_{\text {expes }}$ : end-expiratory plateau esophageal pressure; PTP $_{\text {pt,breath: }}$ pressure-time product of a single breath; PTP vent,breath: $_{\text {pressure- }}$ time product of a mechanical ventilator for each breath; PEEP: positive end expiratory pressure; PTP tot, breath: total pressure-time product for each breath;

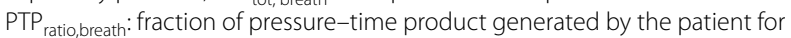
each breath; PMI: pressure muscle index; $\mathrm{P}_{\text {occl }}$ : negative swing in $\mathrm{P}_{\text {aw }}$ generated by respiratory muscle effort during assisted ventilation when the airway is briefly occluded; RR: respiratory rate; RSBI: rapid shallow breathing index, calculated as respiratory rate over tidal volume; $\vee_{\mathrm{T}}$ : tidal volume; $\dot{V}$ : inspiratory flow.
} 


\section{Supplementary Information}

The online version contains supplementary material available at https://doi. org/10.1186/s13054-021-03624-3.

Additional file 1. Association between Flow Index and PTP pt,breath $_{\text {for every }}$ single patient.

\section{Acknowledgements}

Not applicable.

\section{Authors' contributions}

All authors contributed to the data acquisition. F.A., L.P., G.C., F.F. and G.N. drafted the manuscript. G.N. designed and supervised the study. F.A. and G.N. conducted the data analysis. All authors contributed substantially to editing, revising and finalizing the manuscript before submission. All authors approved the final manuscript.

\section{Funding}

No funding was received for this study.

\section{Availability of data and material}

The datasets during and/or analysed during the current study available from the corresponding author on reasonable request.

\section{Declarations}

\section{Ethics approval and consent to participate}

The protocol was approved by the local ethical committee (Comitato Etico della Provincia di Brescia) with protocol number NP2245. Written informed consent was obtained from the patient or, if the patients themselves were not competent, from their next of kin.

\section{Consent for publication}

Not applicable.

\section{Competing interests}

The authors declare that they have no competing interests.

\section{Author details}

'Department of Anesthesia and Intensive Care, Fondazione Poliambulanza, Brescia, Italy. ${ }^{2}$ Department of Anesthesia and Intensive Care, Miulli Regional Hospital, Acquaviva Delle Fonti, Bari, Italy. ${ }^{3}$ Mahidol Oxford Clinical Research Unit (MORU), Bangkok, Thailand. ${ }^{4}$ Department of Anesthesiology, Neurointensive Care Unit, Azienda Ospedaliera Universitaria Careggi, Firenze, Italy. ${ }^{5}$ Department of Anesthesia and Intensive Care, Spedali Civili, Brescia, Italy. ${ }^{6}$ Department of Anesthesia and Intensive Care, Mater Dei Hospital, Bari, Italy. ${ }^{7}$ Department of Anesthesia, I.R.C.C.S. MultiMedica, Sesto San Giovanni, Milano, Italy. ${ }^{8}$ Department of Emergency and Organ Transplantation, University of Bari, Bari, Italy. ${ }^{9}$ Department of Medical and Surgical Specialties, Radiological Sciences and Public Health, University of Brescia, Brescia, Italy. ${ }^{10}$ Department of Intensive Care and Anesthesiology, Fondazione Policlinico, Universitario A. Gemelli, Roma, Italy.

Received: 9 April 2021 Accepted: 31 May 2021

Published online: 07 June 2021

\section{References}

1. Goligher EC, Dres M, Fan E, Rubenfeld GD, Scales DC, Herridge MS, et al. Mechanical ventilation-induced diaphragm atrophy strongly impacts clinical outcomes. Am J Respir Crit Care Med. 2018;197:204-13.

2. Goligher EC, Fan E, Herridge MS, Murray A, Vorona S, Brace D, et al. Evolution of diaphragm thickness during mechanical ventilation. Impact of inspiratory effort. Am J Respir Crit Care Med. 2015;192:1080-8.

3. Telias I, Spadaro S. Techniques to monitor respiratory drive and inspiratory effort. Curr Opin Crit Care. 2020;26:3-10.
4. Yoshida T, Uchiyama A, Matsuura N, Mashimo T, Fujino Y. Spontaneous breathing during lung-protective ventilation in an experimental acute lung injury model: high transpulmonary pressure associated with strong spontaneous breathing effort may worsen lung injury. Crit Care Med. 2012:40:1578-85.

5. Yoshida T, Torsani V, Gomes S, De Santis RR, Beraldo MA, Costa ELV, et al. Spontaneous effort causes occult pendelluft during mechanical ventilation. Am J Respir Crit Care Med. 2013;188:1420-7.

6. Brochard L, Slutsky A, Pesenti A. Mechanical ventilation to minimize progression of lung injury in acute respiratory failure. Am J Respir Crit Care Med. 2017;195:438-42.

7. Goligher EC, Jonkman AH, Dianti J, Vaporidi K, Beitler JR, Patel BK, Yoshida $T$, et al. Clinical strategies for implementing lung and diaphragm-protective ventilation: avoiding insufficient and excessive effort. Intensive Care Med. 2020;46:2314-26.

8. Pletsch-Assuncao R, Caleffi Pereira M, Ferreira JG, Cardenas LZ, de Albuquerque ALP, de Carvalho CRR, et al. Accuracy of invasive and noninvasive parameters for diagnosing ventilatory overassistance during pressure support ventilation. Crit Care Med. 2018;46:411-7.

9. Jung B, Moury PH, Mahul M, de Jong A, Galia F, Prades A, et al. Diaphragmatic dysfunction in patients with ICU-acquired weakness and its impact on extubation failure. Intensive Care Med. 2016;42:853-61.

10. Di Mussi R, Spadaro S, Volta CA, et al. Continuous assessment of neuroventilatory drive during $12 \mathrm{~h}$ of pressure support ventilation in critically ill patients. Crit Care. 2020;24:652.

11. Bertoni M, Telias I, Urner M, Long M, Del Sorbo L, Fan E, et al. A novel non-invasive method to detect excessively high respiratory effort and dynamic transpulmonary driving pressure during mechanical ventilation. Crit Care. 2019;23:346.

12. Yang $\mathrm{KL}$, Tobin MJ. A prospective study of indexes predicting the outcome of trials of weaning from mechanical ventilation. N Engl J Med. 1991;324:1445-50.

13. Karthika M, Al Enezi F, Pillai L, Arabi Y. Rapid shallow breathing index. Ann Thorac Med. 2016;11:167.

14. Yoshida T, Brochard L. Esophageal pressure monitoring: why, when and how? Curr Opin Crit Care. 2018;24:216-22.

15. Benditt JO. Esophageal and gastric pressure measurements. Respir Care. 2005:50:68-75

16. Bertoni M, Spadaro S, Goligher EC. Monitoring patient respiratory effort during mechanical ventilation: lung and diaphragm-protective ventilation. Crit Care. 2020;24:106.

17. Georgopoulos D, Prinianakis G, Kondili E. Bedside waveforms interpretation as a tool to identify patient-ventilator asynchronies. Intensive Care Med. 2006;32:34-47.

18. Arnal JM. Monitoring mechanical ventilation using ventilator waveforms. Berlin: Springer; 2018.

19. Grasso S, Terragni P, Mascia L, Fanelli V, Quintel M, Herrmann P, et al. Airway pressure-time curve profile (stress index) detects tidal recruitment/hyperinflation in experimental acute lung injury. Crit Care Med. 2004;32:1018-27.

20. Boles JM, Bion J, Connors A, Herridge M, Marsh B, Melot C, et al. Weaning from mechanical ventilation. Eur Respir J. 2007;29:1033.

21. Baydur A, Behrakis PK, Zin WA, Jaeger M, Milic-Emili J. A simple method for assessing the validity of the esophageal balloon technique. Am Rev Respir Dis. 1982;126:788-91.

22. Akoumianaki E, Maggiore SM, Valenza F, Bellani G, Jubran A, Loring SH, et al. The application of esophageal pressure measurement in patients with respiratory failure. Am J Respir Crit Care Med. 2014;189:520-31.

23. Mojoli F, lotti GA, Torriglia F, Pozzi M, Volta CA, Bianzina S, et al. In vivo calibration of esophageal pressure in the mechanically ventilated patient makes measurements reliable. Crit Care. 2016;20:98.

24. The PLeUral pressure working Group (PLUG_Acute Respiratory Failure section of the European Society of Intensive Care Medicine), Mauri T, Yoshida T, Bellani G, Goligher EC, Carteaux G, et al. Esophageal and transpulmonary pressure in the clinical setting: meaning, usefulness and perspectives. Intensive Care Med. 2016;42:1360-73.

25. Sun XM, Chen GQ, Chen K, Wang YM, He X, Huang HW, et al. Stress index can be accurately and reliably assessed by visually inspecting ventilator waveforms. Respir Care. 2018;63:1094-101.

26. Terragni PP, Filippini C, Slutsky AS, Birocco A, Tenaglia T, Grasso S, et al. Accuracy of plateau pressure and stress index to identify injurious 
ventilation in patients with acute respiratory distress syndrome. Anesthesiology. 2013;119:880-9.

27. Stram D, Lee J. Variance components testing in the longitudinal mixed effects model. Biometrics. 1994;50:1171-7.

28. Nakagawa S, Schielzeth H. A general and simple method for obtaining R2 from generalized linear mixed-effects models. Methods Ecol Evol. 2013;4:133-42.

29. Iotti GA, Braschi A, Brunner JX, Palo A, Olivet MC. Noninvasive evaluation of instantaneous total mechanical activity of the respiratory muscles during pressure support ventilation. Chest. 1995;108:208-15.

30. Foti G, Cereda M, Banfi G, Pelosi P, Fumagalli R, Pesenti A. End-inspiratory airway occlusion: a method to assess the pressure developed by inspiratory muscles in patients with acute lung injury undergoing pressure support. Am J Respir Crit Care Med. 1997;156:1210-6.

31. Iotti GA, Braschi A, Brunner JX, Smits T, Olivei M, Palo A, et al. Respiratory mechanics by least squares fitting in mechanically ventilated patients: applications during paralysis and during pressure support ventilation. Intensive Care Med. 1995;21:406-13.

32. Natalini G, Buizza B, Granato A, Aniballi E, Pisani L, Ciabatti G, et al. Noninvasive assessment of respiratory muscle activity during pressure support ventilation: accuracy of end-inspiration occlusion and least square fitting methods. J Clin Monit Comput. 2020. https://doi.org/10.1007/ s10877-020-00552-5.

33. Bellani G, Mauri T, Coppadoro A, Grasselli G, Patroniti N, Spadaro S, et al. Estimation of patient's inspiratory effort from the electrical activity of the diaphragm. Crit Care Med. 2013;41:1483-91.
34. Jansen D, Jonkman AH, Roesthuis L, Gadgil S, van der Hoeven JG, Scheffer $\mathrm{GJ}$, et al. Estimation of the diaphragm neuromuscular efficiency index in mechanically ventilated critically ill patients. Crit Care. 2018;22:238.

35. Bellemare F, Jeanneret A, Couture J. Sex Differences in thoracic dimensions and configuration. Am J Respir Crit Care Med. 2003;168:305-12.

36. Dres M, Demoule A. Monitoring diaphragm function in the ICU. Curr Opin Crit Care. 2020:26:18-25.

37. Umbrello M, Formenti P, Lusardi AC, Guanziroli M, Caccioppola A, Coppola $\mathrm{S}$, et al. Oesophageal pressure and respiratory muscle ultrasonographic measurements indicate inspiratory effort during pressure support ventilation. Br J Anaesth. 2020;125:e148-57.

38. Goligher EC, Laghi F, Detsky ME, Farias P, Murray A, Brace D, et al. Measuring diaphragm thickness with ultrasound in mechanically ventilated patients: feasibility, reproducibility and validity. Intensive Care Med. 2015;41:734.

39. Bellani G, Grassi A, Sosio S, Foti G. Plateau and driving pressure in the presence of spontaneous breathing. Intensive Care Med. 2019;45:97-8.

40. Grasselli G, Brioni M, Zanella A. Monitoring respiratory mechanics during assisted ventilation. Curr Opin Crit Care. 2020;26:11-7.

\section{Publisher's Note}

Springer Nature remains neutral with regard to jurisdictional claims in published maps and institutional affiliations.
Ready to submit your research? Choose BMC and benefit from:

- fast, convenient online submission

- thorough peer review by experienced researchers in your field

- rapid publication on acceptance

- support for research data, including large and complex data types

- gold Open Access which fosters wider collaboration and increased citations

- maximum visibility for your research: over 100M website views per year

At BMC, research is always in progress.

Learn more biomedcentral.com/submissions 